\title{
Plano Plurianual 2016-2019: realismo e aderência ${ }^{1}$
}

Constantino Cronemberger Mendes ${ }^{2}$

Thiago Silva e Souza ${ }^{3}$

Welles Matias de $\mathrm{Abreu}^{4}$

O planejamento governamental é, desde o princípio, matéria de controvérsia sobre sua relevância. As posiçóes compreendem desde a defesa irrestrita, tomando-o como instrumento central da ação pública, à crítica mais feroz, tratando-o como "peça de ficção". Ao longo do tempo, porém, esse mecanismo transpôs diversas etapas de evoluçáo teórica, metodológica e instrumental no mundo e no Brasil, em particular, relacionadas às três principais escolas de planejamento (quadro 1), desde os anos 1960 do século passado (Mintzberg, Ahlstrand e Lampel, 2009).

\section{QUADRO 1}

\section{Período do planejamento brasileiro e sua escola teórica predominante}

\begin{tabular}{|l|l|l|l|}
\hline \multicolumn{2}{|c|}{ Período do planejamento brasileiro } & \multicolumn{2}{c|}{ Características da escola predominante } \\
\hline 1964-1985 & $\begin{array}{l}\text { Planos nacionais de } \\
\text { desenvolvimento: modelo PPBS }\end{array}$ & Escola clássica & $\begin{array}{l}\text { Integra programa-orçamento; utiliza cenários descritivos e preditivos } \\
\text { periódicos, incrementais e formais; foco nos planejadores }\end{array}$ \\
\hline 1986-1999 & $\begin{array}{l}\text { Hiperinflação e crise externa } \\
\text { restringem a formalização (planos } \\
\text { de estabilização) }\end{array}$ & $\begin{array}{l}\text { Escola de posicionamento } \\
\text { Destratégia genérica, em bases analíticas frequentes, sistemáticas } \\
\text { e ocasionais sobre competitividade e portfólio de projetos, sem } \\
\text { preocupação formal; foco nos analistas }\end{array}$ \\
\hline $\begin{array}{l}\text { Pós-reforma gerencial: programas } \\
\text { com prioridades de governo } \\
\text { (modelo PES) }\end{array}$ & Escola de configuração & $\begin{array}{l}\text { Reformulação periódica das prioridades, visando ao novo estágio da } \\
\text { realidade, a partir da situação inicial; foco na participação }\end{array}$ \\
\hline
\end{tabular}

Elaboração dos autores.

Obs.: PPBS - Planning, Programming, and Budgeting System; PES - Planejamento Estratégico Situacional.

Constata-se, em pouco mais de cinquenta anos, o planejamento passando de uma simples programação incremental para a construção de programas estratégicos e prioritários das agendas de governo, adotados no modelo de planejamento plurianual, em conjunto com dispositivos anuais: Lei de Diretrizes Orçamentárias (LDO) e Lei Orçamentária Anual (LOA).

A partir da promulgação da Constituição de 1988 (CF/1988), foram aprovados oito planos plurianuais (PPAs), consistindo em material importante de análise das escolhas públicas no atendimento das demandas da sociedade. Os "ciclos políticos" associados aos planos podem ser analisados por meio dos modelos de planejamento específicos adotados pelos diversos governos ao longo do tempo. Cada modelo compreende diretrizes estratégicas e opçóes prioritárias de políticas públicas, bem como ações específicas a serem implementadas para o alcance dos objetivos e das metas dos programas de governo.

1. DOI: http://dx.doi.org/10.38116/bapi28art1

2. Técnico de planejamento e pesquisa na Diretoria de Estudos e Políticas Regionais, Urbanas e Ambientais (Dirur) do Ipea; e ex-subsecretário de planejamento governamental do Ministério da Economia.

3. Capitão de corveta; e subcoordenador adjunto de orçamento na Secretaria-Geral da Marinha.

4. Analista de planejamento e orçamento da Secretaria de Orçamento Federal (SOF); coordenador na Auditoria Interna da Agência Nacional de Águas (ANA); e pesquisador independente em governança e gestão pública. 
Os PPAs compreendem um conjunto de programas, composto de açôes orçamentárias e outros atributos, elaborado a partir de diagnósticos de problemas sociais, cujas causas devem ser enfrentadas pelo poder público. Avalia-se o grau de aderência como indicador de performance executiva entre a alocação orçamentária proposta, considerando os objetivos e as metas dos programas adotados, e os efetivos resultados alcançados. Considera-se que, quanto maior (menor) a aderência entre o proposto e o realizado, maiores (menores) os efeitos setoriais alocativos e distributivos da execução orçamentária. Analisa-se, ainda, o grau de realismo como indicador de precisão dos cenários macroeconômicos previstos no plano, quanto ao realizado no período, tendo em vista a função pública do equilíbrio macroeconômico. Essa abordagem analítica está, assim, associada ao arcabouço teórico da despesa orçamentária e das finanças públicas (Musgrave, 1959).

O PPA 2016-2019 foi o último plano de governo totalmente implementado e, portanto, passível de análise integral do grau de aderência e do grau de realismo, dados os parâmetros previstos e efetivos no período. Trata-se de um contraponto analítico na dimensão estratégica, que aborda o cenário macroeconômico, e na dimensão tática, que versa sobre objetivos e metas dos programas temáticos.

Esse PPA foi elaborado no primeiro ano do governo federal reeleito em 2014, sugerindo uma continuidade programática do PPA 2012-2015. O novo plano era parte de um "projeto nacional de desenvolvimento que vinha sendo implantado há mais de uma década buscando conciliar crescimento econômico com distribuição da renda e inclusão social" (Brasil, 2015, p. 8). Entende-se, assim, que a diretriz estratégica do PPA 2016-2019 estava delineada desde o PPA 2004-2007. Considera-se, ainda, que o PPA 2016-2019 tenha revisto prioridades, objetivos e metas do plano anterior, adaptando-os à realidade vigente na época.

Essa diretriz é detalhada na dimensão programática do plano em análise, por meio de programas temáticos e de gestão, indicando compromissos, objetivos e metas do governo no seu período de vigência. A proposta do PPA 2016-2019 teria, em tese, internalizado a experiência do(s) plano(s) anterior(es), ajustando-o(s), conferindo aderência e realismo ao proposto no novo plano em um ambiente macroeconômico adverso vigente na época. A aposta, contudo, foi outra.

A proposta encaminhada pelo Poder Executivo ao Congresso Nacional, em 31 de agosto 2015, foi publicada como Lei no 13.249, de 14 de janeiro de 2016. Na dimensão estratégica, o cenário macroeconômico do plano considerava "um quadro macroeconômico desafiador" para o período (Brasil, 2015, p. 20). A proposta, porém, buscou absorver o impacto da crise financeira internacional de 2008, adotando uma política macroeconômica expansiva, apoiada em investimentos públicos - Programa de Aceleração do Crescimento (PAC), fase 2 -, em investimentos em logística Programa de Investimentos em Logística (PIL) e programa Minha Casa Minha Vida (MCMV) - e em subsídios - desoneração de impostos e crédito barato ao setor privado.

O ano de 2014 é considerado o ponto de inflexão da economia nacional para um ambiente recessivo, após a primeira fase da referida crise financeira. Ou seja, os parâmetros macroeconômicos do PPA 2012-2015 já estariam "contaminados" com os efeitos de uma das mais fortes crises financeiras internacionais, passíveis de consideração durante a implementação do PPA 2008-2011, impactado negativamente quanto aos seus resultados esperados.

O descompasso entre o ambiente econômico vigente na época e o proposto no plano explicaria, como primeira hipótese, o baixo grau de realismo do PPA 2016-2019. A aposta otimista ("irrealista") 
no cenário macroeconômico interno se reflete na dimensão tática do plano, por meio dos programas temáticos, que, dado esse descompasso, tenderiam a ter um baixo grau de aderência, como segunda hipótese, entre os objetivos e as metas propostas e os resultados efetivos alcançados.

Para confirmar ou não essas hipóteses, o primeiro passo compara parâmetros (tabela 1) utilizados no cenário macroeconômico plurianual do plano, atualizados a cada LDO, aos dados efetivos de cada exercício no período 2016-2019. Todavia, apesar de sua previsão legal, ${ }^{5}$ náo se observa a análise do comportamento das variáveis macroeconômicas, assim como as razóes das discrepâncias verificadas entre os valores previstos e realizados no Relatório Anual de Avaliação (Brasil, 2020), o que permite, de antemão, a indicação de certo grau de irrealismo das projeçôes.

TABELA 1

PPA 2016-2019: variáveis macroeconômicas (valor previsto versus valor efetivo)

1 A - PIB, IPCA, Selic e câmbio: valores previstos (projetos de lei PPA e LDO) e efetivos

\begin{tabular}{|c|c|c|c|c|c|c|c|c|c|c|c|c|}
\hline & \multicolumn{3}{|c|}{ PIB (\%) } & \multicolumn{3}{|c|}{ IPCA (\%) } & \multicolumn{3}{|c|}{ Selic (\%) } & \multicolumn{3}{|c|}{ Câmbio (R\$) } \\
\hline & PLPPA & PLDO & Efetivo & PLPPA & PLDO & Efetivo & PLPPA & PLDO & Efetivo & PLPPA & PLDO & Efetivo \\
\hline 2016 & 0,2 & 1,3 & $-3,6$ & 5,4 & 5,6 & 6,3 & 12,0 & 11,5 & 14,1 & 3,40 & 3,30 & 3,50 \\
\hline 2017 & 1,7 & 1,0 & 1,0 & 4,5 & 6,0 & 2,9 & 10,8 & 12,8 & 9,9 & 3,50 & 4,40 & 3,20 \\
\hline 2018 & 2,0 & 2,5 & 1,1 & 4,5 & 4,5 & 3,7 & 10,0 & 9,0 & 6,5 & 3,50 & 3,40 & 3,70 \\
\hline 2019 & 2,5 & 3,0 & 0,8 & 4,5 & 4,3 & 3,8 & 10,0 & 8,0 & 6,2 & 3,50 & 3,40 & 3,80 \\
\hline
\end{tabular}

1B - Resultado primário, dívidas líquida e bruta e resultado nominal: valores previstos (projetos de lei PPA e LDO) e efetivos

\begin{tabular}{|c|c|c|c|c|c|c|c|c|c|c|c|c|}
\hline & \multicolumn{3}{|c|}{$\begin{array}{c}\text { Resultado primário no governo } \\
\text { central (\% do PIB) }\end{array}$} & \multicolumn{3}{|c|}{ DLSP consolidado (\% do PIB) } & \multicolumn{3}{|c|}{ DBGG (\% do PIB) } & \multicolumn{3}{|c|}{$\begin{array}{l}\text { Resultado nominal no setor } \\
\text { público (\% do PIB) }\end{array}$} \\
\hline & PLPPA & PLDO & Efetivo & PLPPA & PLDO & Efetivo & PLPPA & PLDO & Efetivo & PLPPA & PLDO & Efetivo \\
\hline 2016 & $-0,5$ & 2,0 & $-2,6$ & 39,0 & 34,9 & 46,3 & 68,4 & 61,9 & 77,4 & $-5,9$ & $-2,9$ & $-7,6$ \\
\hline 2017 & 1,1 & 0,1 & $-1,7$ & 40,2 & 41,5 & 51,6 & 68,8 & 73,0 & 83,1 & $-3,5$ & $-5,7$ & $-7,0$ \\
\hline 2018 & 1,7 & $-1,8$ & $-1,6$ & 40,1 & 54,1 & 54,1 & 68,2 & 76,9 & 87,0 & $-2,6$ & $-7,0$ & $-6,2$ \\
\hline 2019 & 1,7 & $-1,8$ & $-1,8$ & 39,9 & 58,9 & 54,8 & 67,3 & 77,7 & 87,7 & $-2,6$ & $-7,1$ & $-6,4$ \\
\hline
\end{tabular}

Fonte: Banco Central do Brasil (BCB), Secretaria do Tesouro Nacional (STN) e Instituto Brasileiro de Geografia e Estatística (IBGE).

Obs.: PIB - produto interno bruto; IPCA - Índice de Preços ao Consumidor Amplo; PLPPA - Projeto de Lei do Plano Plurianual; PLDO - Projeto de Lei de Diretrizes Orçamentárias; DLSP - dívida líquida do setor público; DBGG - dívida bruta do governo geral.

Exceto os parâmetros relacionados à política monetária (inflação, taxa de juros e, com restrições, câmbio), revelando resultados efetivos positivos, todos os demais parâmetros - relacionados à política fiscal - tiveram resultados efetivos piores que os valores esperados, mesmo considerando as projeçóes atualizadas anualmente nas LDOs. Note-se que o Relatório Focus do BCB, de 31 de dezembro de 2015, previa, para 2016: PIB de -3\%; IPCA de 6,9\%; Selic de 15,2\%; câmbio de R \$/US\$ 4,20; e DLSP de 40\% do PIB. A despeito da existência de incerteza nas previsóes, as diferenças persistem e acentuam no período, o que, para fins desta análise, demonstra um grau de realismo baixo do plano.

A diferença entre o projetado e o efetivo no contexto macroeconômico, a cada ano, reflete na maior ou menor restrição orçamentária do governo federal, com implicaçóes na implementação das açóes setoriais. Assim, as escolhas prioritárias devem ser revistas anualmente para compatibilizar os recursos disponíveis entre os programas previstos no plano. Alguns seriam mais ou menos impactados,

5. Ver inciso II do art. 13, disponível em: <encurtador.com.br/anyN5>. 
dependendo da obrigatoriedade (a exemplo da educação e da saúde) e da prioridade concedida pelo Poder Executivo na execução orçamentária, com reflexos diretos nas metas setoriais.

Há de se ressaltar que, em dezembro de 2016, o país, no seu terceiro ano de deficit primário, implanta o Novo Regime Fiscal (NRF) (Emenda Constitucional no 95/2016), como instrumento completar à Lei de Responsabilidade Fiscal (LRF) e à Regra de Ouro. O denominado teto de gastos deveria gerar um senso maior de realismo da (baixa) capacidade do governo de atender ao previsto na programação. Assim, por meio de revisóes periódicas da capacidade orçamentária, poderia haver ajustes programáticos, proporcionando uma maior aderência entre o previsto e o realizado.

O dispositivo não soluciona o engessamento do orçamento público, que, em pouco tempo, dado o alto nível de despesas obrigatórias, inviabilizará a ação discricionária do Estado na implementação de políticas públicas em favor de restriçóes fiscais de curto prazo. Após a Emenda Constitucional no 95/2016, observa-se a retomada do resultado primário, buscando equilibrar as contas públicas via crescimento da receita líquida e estabilidade do nível de despesas (gráfico 1).

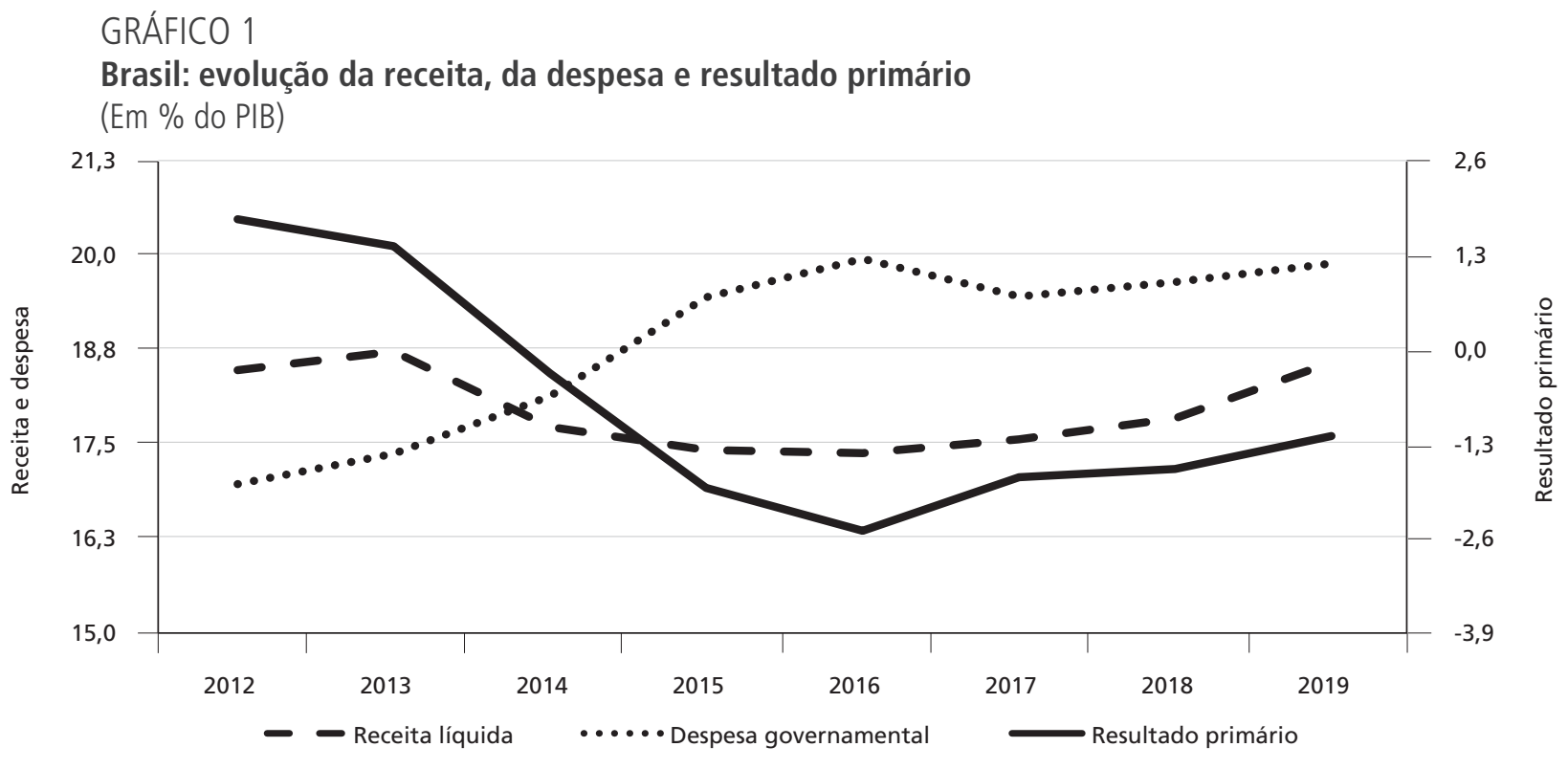

Fonte: STN.

A dimensão tática do PPA 2016-2019 apresenta 54 programas temáticos, 303 objetivos, 1.132 metas e 564 indicadores, entre outros atributos, detalhando a estratégia para cada área de atuação governamental. O grau de aderência dos resultados programáticos pode ser tratado por diversos parâmetros, ${ }^{6}$ tais como: nível de execução física ou financeira; e indicadores de produto e de resultados - nesse caso, de impacto da ação pública na realidade local dos beneficiários.

$\mathrm{Na}$ execução efetiva do orçamento (sem refinanciamento da dívida e transferências de receita) do plano, os valores anuais pagos (incluídos os restos a pagar) tiveram reduçóes do valor planejado ou autorizado, de acordo com o Siga Brasil, 7 em 12,9\% (2016), 25,7\% (2017), 24,3\% (2018) e 14,7\% (2019). Nos investimentos - grupo de natureza da despesa (GND) 4 -, variável de ajuste

6. A metodologia no PPA 2016-2019 adota diferentes quantidades de objetivos, metas e indicadores, provocando complexidades no relacionamento entre esses atributos e remetendo à adoção de critérios simplificados na avaliação da aderência entre proposto e efetivo.

7. Disponível em: <https://www12.senado.leg.br/orcamento/sigabrasil>. 
nas contas públicas em períodos de crise fiscal, o valor pago (incluídos os restos a pagar) teve queda relativa ao planejado de 15,2\% (2016), 36,7\% (2017), 28,8\% (2018) e 44,4\% (2019).

Em termos funcionais, desconsiderando Previdência Social, encargos especiais e reserva de contingência, os únicos setores com recursos pagos maiores que o planejado, entre 2016 e 2019, foram habitação $(63,4 \%)$ e saneamento $(107 \%)$. As demais 24 funçóes tiveram perdas em recursos pagos, relativos aos valores planejados (autorizados): urbanismo (35,3\%), comércio e serviços $(32,1 \%)$, agricultura $(22,7 \%)$, desporto e lazer $(18,2 \%)$, organização agrícola $(14,8 \%)$, cultura $(14,0 \%)$, gestão ambiental (12,7\%), transporte (10,5\%), administração (10,4\%), energia $(7,8 \%)$ e indústria $(7,5 \%)$, educação $(6,4 \%)$, legislativa $(6,1 \%)$, comunicação $(5,2 \%)$, trabalho $(4,5 \%)$, saúde $(3,7 \%)$, cidadania $(3,7 \%)$, judiciário $(3,6 \%)$, essencial à justiça $(2,7 \%)$, defesa nacional $(1,7 \%)$, ciência e tecnologia $(1,3 \%)$, segurança pública $(1,0 \%)$, relaçóes exteriores $(0,8 \%)$ e assistência social $(0,2 \%)$.

Esses resultados sugerem que as metas programáticas globais e por setor do plano, baseadas no valor autorizado, sofreram efeitos negativos com a queda de recursos pagos. Esses impactos náo necessariamente foram maiores nos setores com maiores perdas, considerando que os recursos previstos podem ser, também, maiores - e vice-versa. É possível, ainda, que a redução dos recursos aplicados resulte em resultados efetivos maiores, revelando eficiência da ação pública. Assim, outros parâmetros serão utilizados para testar a hipótese do (baixo) grau de aderência do plano.

Os indicadores e as metas referentes aos programas temáticos do PPA 2016-2019 permitem, também, avaliar o seu grau de aderência. No exercício de 2016, dos 564 indicadores avaliados (100\% do total) (Brasil, 2017), houve alguma melhora em 252 (45\%); piora em 232 (41\%); 26 (5\%) não sofreram alteração; e 54 (10\%) não apresentaram desempenho, por falta de coleta de dados, inexistência de índice de referência ou efeito não identificado.

Em 2017, a análise cobriu 573 indicadores (Brasil, 2018), 9 acima do total previsto no plano, revelando alguma melhora em 328 (57\%) e piora em 186 (32\%). Outros 12 indicadores (2\%) tiveram resultados estáveis e 47 (8\%) não apresentaram apuração.

No exercício seguinte, os resultados cobriram 542 indicadores (96\% do total) (Brasil, 2019), mostrando alguma melhora em 225 (39\%) e piora em 158 (28\%), enquanto 157 (28\%) não sofreram alteração e $33(6 \%)$ não tiveram efeito identificado.

Finalmente, em 2019, os resultados de 502 indicadores (92\% do total) no Sistema Integrado de Planejamento e Orçamento (Siop) do governo federal mostram 298 (59\%) apresentando melhora, 178 (36\%) exibindo piora, 12 (2\%) sem alteração e 14 (3\%) não disponíveis.

Em suma, nos indicadores analisados no período 2016-2019, cujo menor número foi avaliado nos últimos dois anos, a média global apresenta alguma melhora em 50\% dos resultados, com outra metade apresentando piora, estabilidade ou nenhum efeito. Adicionalmente, considerando o conjunto de 755 metas (67\% do total de 1.132 previstas) dos programas temáticos, dados do Siop no período quadrienal revelam 450 metas (60\%) não alcançadas, 273 (36\%) alcançadas e 32 (4\%) não declaradas. Para os objetivos desta análise, portanto, considera-se que o grau de aderência dos resultados do referido PPA, diante do projetado, foi baixo.

A constatação de baixos graus de realismo e de aderência do PPA 2016-2019 não atesta a irrelevância do planejamento governamental. A análise revela, de fato, que o planejamento de médio prazo deveria ser pautado por modelos flexíveis, adaptáveis às realidades específicas 
conjunturais e estruturais. Mesmo países com setor privado forte, capazes de resolver problemas alocativos e estabilizadores via mercado, têm no planejamento um instrumento com função pública de teor distributivo.

No Brasil, o PPA é fonte de questionamentos constantes, em face, entre outras coisas, de sua natureza burocrática e de sujeição ao orçamento rígido e incrementalista, conferindo ao instrumento uma "peça de ficção". O caráter fiscalista da política econômica dá ao orçamento um papel eminentemente estabilizador, apoiando a política monetária, sem função distributiva ou alocativa. Os parâmetros macroeconômicos do PPA 2016-2019 (tabela 1) indicam, porém, que a política fiscal "descolou" da política monetária, não promovendo estabilidade econômica, mas com efeitos distributivos e alocativos relevantes, captados nos resultados dos programas temáticos.

Particularmente em contexto macroeconômico recessivo, vigente no Brasil desde 2014, torna-se imprescindível uma ação pública eficiente, eficaz e efetiva nas suas funções alocativas, distributivas e estabilizadoras. Nesse contexto, o planejamento se torna ainda mais importante, considerando sua função orientadora e estratégica ao orçamento, e também no caráter político, com a sociedade realizando escolhas e definindo prioridades por seus representantes no Executivo, Legislativo e Judiciário.

A provisão de bens e serviços públicos, dadas as falhas de mercado, constitui objeto de discussão sobre a melhor alocação de recursos públicos por meio do mecanismo de planejamento-orçamento. A responsabilidade constitucional, nessa provisão de que atendam às necessidades heterogêneas e às desiguais da sociedade, revela o teor distributivo da ação pública. O caráter fiscal dessa ação considera, ainda, o papel estabilizador desse instrumento, em complemento à política monetária.

Nesse contexto, o planejamento exige flexibilidade diante do "ciclo político" quadrienal e da proposição e implementação de estratégias e prioridades governamentais específicas. Isso não significa descontinuidade da ação pública, dado o senso comum de separar "política de governo" de "política de Estado". A CF/1988 compreende a base da política de Estado. O PPA constitui um instrumento de planejamento-orçamento concernente à política de governo. Assim, algumas questôes são levantadas: o PPA deve ter caráter infralegal? Como isso refletiria na relaçáo com o orçamento, este sendo lei? No PPA, como lei, caberia maior flexibilidade, reorientando o orçamento de acordo com as necessidades conjunturais? Como o PPA pode constituir referencial estratégico efetivo de governança pública, com foco em liderança e controle? Tudo isso daria maior realismo e aderência ao plano?

A relevância ou não do planejamento plurianual depende de respostas adequadas aos questionamentos anteriores, no sentido de promover maior realismo e aderência entre os seus resultados esperados e efetivos. O sistema de planejamento-orçamento precisa levar em conta os papéis alocativo, distributivo e estabilizador das funçôes de Estado, submetido às suas responsabilidades constitucionais e legais. Isso não exclui a possibilidade de incorporar, na ação pública, o relevante papel complementar alocativo, particularmente, do setor privado e do mercado.

Ademais, destacam-se as resoluçóes do Tribunal de Contas da União (TCU) sobre o PPA 2016-2019 (acórdãos nos 2.127/2017 e 2.608/2018), apresentando sugestôes ao aprimoramento do instrumento, no sentido de: ser planejamento efetivo de médio prazo do governo federal; contribuir para a governança orçamentária; institucionalizar processos contínuos de gestão estratégica e de riscos; promover monitoramento e avaliação; e integrar um plano nacional de longo prazo. 
Finalmente, o planejamento envolve atividades de avaliação das políticas públicas na construção de cenários macroeconômicos e na implementação de programas e açóes consistentes ao enfrentamento dos problemas da sociedade. A avaliação retroalimenta e aprimora o ciclo de planejamento, orçamento e gestão, dotando o instrumento de maior realismo e aderência. A execução e a gestão orçamentária perseguindo realmente as metas previstas no PPA podem alcançar graus de realismo e de aderência mais adequados ao planejamento governamental.

\section{REFERÊNCIAS}

BRASIL. PPA 2016-2019: desenvolvimento, produtividade e inclusão social - mensagem presidencial. Brasília: Ministério do Planejamento, Orçamento e Gestão, 2015.

. Relatório anual de avaliação: PPA 2016-2019 - ano-base 2016. Brasília: Ministério da Economia, 2017.

Relatório anual de avaliação: PPA 2016-2019 - ano-base 2017. Brasília: Ministério da Economia, 2018.

. Relatório anual de avaliação: PPA 2016-2019 - ano-base 2018. Brasília: Ministério da Economia, 2019.

Relatório anual de avaliaçáo: PPA 2016-2019 - ano-base 2019. Brasília: Ministério da Economia, 2020.

MINTZBERG, H.; AHLSTRAND, B.; LAMPEL, J. Safári da estratégia: um roteiro pela selva do planejamento estratégico. Porto Alegre: Bookman Editora, 2009.

MUSGRAVE, R. A. The theory of public finance. New York: McGraw Hill, 1959. 
